\title{
KIT is highly expressed in adenoid cystic carcinoma of the breast, a basal-like carcinoma associated with a favorable outcome
}

Sandy Azoulay ${ }^{1}$, Marick Laé ${ }^{1}$, Paul Fréneaux ${ }^{1}$, Solange Merle ${ }^{1}$, Abir Al Ghuzlan ${ }^{1}$, Caroline Chnecker ${ }^{1}$, Christophe Rosty ${ }^{1}$, Jerzy Klijanienko ${ }^{1}$, Brigitte Sigal-Zafrani ${ }^{1, *}$, Rémy Salmon ${ }^{2}$, Alain Fourquet ${ }^{3}$, Xavier Sastre-Garau ${ }^{1}$ and Anne Vincent-Salomon ${ }^{1}$

${ }^{1}$ Department of Pathology, Institut Curie, Paris Cedex, France; ${ }^{2}$ Department of Surgery, Institut Curie, Paris Cedex, France and ${ }^{3}$ Department of Radiotherapy, Institut Curie, Paris Cedex, France

\begin{abstract}
Recent biological studies have classified breast carcinomas into HER2-overexpressing, estrogen receptorpositive/luminal, basal- and normal-like groups. According to this new biological classification, the objectives of our study were to assess the clinical, morphologic and immunophenotypic characteristics of adenoid cystic carcinoma of the breast in order to classify this subtype of breast carcinoma. A total of 18 cases of adenoid cystic carcinoma were identified from the Institut Curie files. Clinical information was available for 16 patients with a median follow-up of 6.5 years. Morphologically, all tumors were graded according to the system defined by Kleer and Oberman (histologic and nuclear grade). Immunophenotype was assessed with anti-ER, PR, HER2, KIT, basal (CK5/6) and luminal cytokeratins (CK8/18) and p63 antibodies. One out of 18 tumors was nuclear grade $1(16 \%)$, nine were nuclear grade $2(50 \%)$ and eight were nuclear grade $3(44 \%)$. All cases were estrogen receptor, progesterone receptor and HER-2 negative. Epithelial cells were strongly positive around glandular lumina with one or both cytokeratins, identifying the coexistence of CK5/6 + cells, CK5/6 and CK8/18 + cells, CK8/18 + cells and p63 + cells. All cases $(100 \%)$ were also KIT positive. In all, 15 patients were treated by surgery. Nine of them received adjuvant radiotherapy. Follow-up was available for 16 patients. In all, 14 patients were alive. Two of them, initially treated by surgery only, presented a local recurrence. Two patients died (one of them treated by radiation therapy only died from her disease). Our study shows that adenoid cystic carcinoma of the breast is a special, estrogen receptor, progesterone receptor, HER-2 negative and highly KIT-positive, basal-like breast carcinoma, associated with an excellent prognosis. This highly specific immunophenotype could be useful to differentiate adenoid cystic carcinoma of the breast from other subtypes of breast carcinoma such as cribriform carcinoma.

Modern Pathology (2005) 18, 1623-1631. doi:10.1038/modpathol.3800483; published online 2 September 2005
\end{abstract}

Keywords: adenoid cystic carcinoma; basal carcinoma; breast; CD117; Cytokeratins; HER2; KIT

Adenoid cystic carcinoma of the breast is a rare tumor, which represents less than $1 \%$ of all mammary carcinomas. ${ }^{1}$ Although adenoid cystic carcinoma of the breast is morphologically indistinguishable from adenoid cystic carcinoma of the salivary glands, its prognosis is quite different: adenoid cystic carcinoma of the breast has an

Correspondence: Dr A Vincent-Salomon, MD, Institut Curie, service de Pathologie, 26 rue d’ULM, 75248 Paris cedex 05, France.

E-mail: anne.salomon@curie.net

* On behalf of the Breast Cancer Study Group.

Received 29 April 2005; revised and accepted 15 July 2005; published online 2 September 2005 excellent prognosis, while adenoid cystic carcinoma of the salivary gland has an aggressive course..$^{2-6}$ Histologically, adenoid cystic carcinoma is characterized by invasive proliferation of circumscribed clusters of cells forming solid, cribriform, tubular and trabecular arrangements with one pattern that can predominate. Two populations of cells coexist within the tumor: a usually predominant population, classically referred to basal-like cells, and a minor population of cells with large bright eosinophilic cytoplasm. Immunohistochemical studies have shown that adenoid cystic carcinoma of the breast are estrogen receptor (ER)-negative tumors composed of a double population of cells: epithelial cytokeratin-positive cells, and myoepithelial, 
vimentin and S100 protein-positive cells. ${ }^{7-10}$ Recent descriptions have identified two distinct molecular weight cytokeratins (CK) as markers of different population of breast gland epithelium; CK8/18 (low molecular weight CK) expressed by luminal cells and CK5/6 (high molecular weight CK) expressed by basal cells. ${ }^{11}$ Stem cells, which have the capacity to differentiate towards either glandular or basal phenotype, have also been identified. Therefore, five distinct cell populations have been identified within the mammary gland: committed stem cell $(\mathrm{CK} 5 / 6+)$, glandular precursor cell $(\mathrm{CK} 5 / 6+$, CK8/ $18+)$, glandular end cell $(\mathrm{CK} 8 / 18+)$, myoepithelial precursor cell $(\mathrm{CK} 5 / 6+)$ and myoepithelial cells. ${ }^{12}$ To investigate this new biological concept in adenoid cystic carcinoma of the breast, we examined the expression of CK8/18, CK5/6, and p63 (as a myoepithelial marker) ${ }^{13}$ in a series of 18 adenoid cystic carcinomas of the breast. Moreover, recent studies have revealed that KIT (CD117), a transmembrane tyrosine kinase receptor encoded by the protooncogene $C$-KIT, is expressed in $90 \%$ of adenoid cystic carcinomas of the salivary gland but not in normal salivary gland tissue or other head and neck neoplasms. ${ }^{14-16}$ This prompted us to determine whether a similar pattern of KIT reactivity could be found in adenoid cystic carcinoma of the breast.

In this study, we observed that adenoid cystic carcinoma of the breast presented a favorable outcome that contrasts with their basal-like immunophenotype characterized by $100 \%$ HER2, ER and PR negativity associated with $100 \%$ KIT positivity. To our knowledge, our study is the first to demonstrate that adenoid cystic carcinoma of the breast presents a highly characteristic immunophenotype with implications for differential diagnosis.

\section{Materials and methods}

In all, 18 patients with adenoid cystic carcinoma of breast were identified from the archives of the Department of Pathology of the Institut Curie, between 1974 and 2004. Two pathologists (SA and AVS) retrospectively reviewed hematoxylin-eosinsafran-stained sections. Three histologic grades were defined according to the system defined by Kleer and Oberman using both a histologic grade defined as grade I corresponding to completely tubular and cribriform tumors without any solid areas, grade II corresponding to tumors containing less than $30 \%$ of solid areas; and grade III corresponding to tumors with more than $30 \%$ of solid areas, and a nuclear grade. Nuclear grade 1 comprised mild cytologic atypia and rare mitotic figures (0-1 mitoses/10 high-power fields (HPF)). Nuclear grade 3 tumors exhibited a higher degree of cytologic atypia, containing cells with prominent nucleoli and a slight increase in mitotic rate (5-10 mitoses/10 HPF). Nuclear grade 2 tumors had intermediate features.
Table 1 Clone, source, and dilution of primary antibodies used for immunohistochemical analysis of adenoid cystic carcinomas of the breast

\begin{tabular}{llll}
\hline Antibody & Clone & Source & Dilution \\
\hline Cytokeratin 5/6 & D5/16B4 & Dako & $1 / 50$ \\
Cytokeratin 8/18 & DC 10 & Zymed & $1 / 100$ \\
Smooth muscle actin & 1A4 & Dako & $1 / 50$ \\
p63 & 4A4 & Dako & $1 / 50$ \\
Estrogen receptor & 6F11 & Novocastra & $1 / 200$ \\
Progesterone receptor & 1A6 & Novocastra & $1 / 200$ \\
HER2 & CB11 & Novocastra & $1 / 1000$ \\
KIT (CD117) & Polyclonal & Dako & $1 / 100$ \\
\hline
\end{tabular}

Immunostainings were performed on $4 \mu \mathrm{m}$ tissue sections prepared from a representative sample of the tumor. After rehydration and antigenic retrieval in citrate buffer $(10 \mathrm{mM}, \mathrm{pH}$ 6.1), tissue sections were stained for ER, progesterone receptor (PR), HER-2, CD117 (an epitope of KIT), CK5/6, CK8/18 and p63. Source, dilution procedures are listed in Table 1. Staining was revealed with the Vectastain Elite ABC peroxidase mouse IgG kit (Vector Burlingame, CA, USA) using diamino-benzidine (Dako A/S, Glostrup, Denmark) as chromogen. One demonstrative case was studied with a double staining procedure using two different pairs of antibodies to document coexpression of CK5/6 and CK8/18 for one pair and CK5/6 and p63 for the other pair, revealed by two chromogens (amino-ethylcarbazole chromogen for CK8/18 and diamino-benzidine chromogen for CK 5/6). Positive nuclear staining for ER, PR and P63 was recorded according to standardized guidelines. For HER-2, only membranous staining was interpreted, as previously defined. ${ }^{17}$ Expression of CD117, CK5/6, CK8/18 was scored positive if any cytoplasmic and/or membranous tumor cell staining was observed. Results were assessed using a three-point scoring system; $0=$ no tumor cell stained, $1 \leq 10 \%$ of tumor cells stained, $2=10-50 \%$ of tumor cells stained and $3 \geq 50 \%$ of tumor cells stained. Internal and external controls were included in the experiments for each antibody.

\section{Results}

\section{Clinical Findings}

Follow-up and clinical information were obtained for 16 patients (Table 2). All patients were females between the ages of 32 and 81 years with a mean age of 56 years. In all, 13 women were postmenopausal and four received hormone replacement therapy. At the time of diagnosis, none of the patients presented suspicious axillary lymph nodes or metastatic disease. In all, 15 patients underwent primary surgery: 12 patients were treated by lumpectomy and three patients by mastectomy. Nonsentinel axillary lymph node dissection was performed in 
Table 2 Clinical and pathologic findings in 18 cases of adenoid cystic carcinoma of the breast

\begin{tabular}{|c|c|c|c|c|c|c|c|c|c|c|c|}
\hline \multirow[t]{2}{*}{ Case } & \multirow{2}{*}{$\begin{array}{c}\text { Age } \\
\text { (years) }\end{array}$} & \multirow[t]{2}{*}{ Menopause } & \multirow{2}{*}{$\begin{array}{c}\text { Size } \\
(\mathrm{mm})\end{array}$} & \multicolumn{2}{|c|}{ Grade } & \multirow[t]{2}{*}{$M I$} & \multirow[t]{2}{*}{ Surgery } & \multirow{2}{*}{$\begin{array}{c}\text { Clinical axillary } \\
\text { lymph node } \\
\text { status } \\
\text { (pathologic) }\end{array}$} & \multirow{2}{*}{$\begin{array}{l}\text { Radio- } \\
\text { therapy }\end{array}$} & \multirow{2}{*}{$\begin{array}{c}\text { Follow-up } \\
\text { (years) }\end{array}$} & \multirow[t]{2}{*}{ Outcome } \\
\hline & & & & Histologic & Nuclear & & & & & & \\
\hline 1 & 47 & + & 25 & III & 2 & 5 & $\mathrm{~L}^{\mathrm{a}}$ & No $(0 / 10)$ & + & 11 & NED \\
\hline 2 & 67 & + & 10 & III & 3 & 1 & $\mathrm{~L}^{\mathrm{a}}$ & No $(0 / 12)$ & - & 9 & NED \\
\hline 3 & 61 & + & 20 & $\mathrm{I}$ & 1 & 2 & $\mathrm{~L}$ & No & - & 19 & $\begin{array}{l}R \text { at } 11 \text { and } \\
14 \text { years }\end{array}$ \\
\hline 4 & 52 & + & 25 & II & 3 & 7 & $\mathrm{~L}$ & No & - & 3 & NED \\
\hline 5 & 55 & + & 65 & $\mathrm{I}$ & 2 & 8 & $\mathrm{M}^{\mathrm{a}}$ & No $(0 / 7)$ & - & 4 & NED \\
\hline 6 & 63 & + & 70 & II & 3 & 8 & $\mathrm{M}^{\mathrm{a}}$ & No $(0 / 15)$ & + & 3 & NED \\
\hline 7 & 34 & - & 16 & II & 3 & 6 & $\mathrm{~L}$ & No & + & 15 & NED \\
\hline 8 & 49 & - & 35 & III & 3 & 2 & $\mathrm{~L}$ & No & - & 20 & $\begin{array}{l}\mathrm{R} \text { at } 13 \\
\text { years }\end{array}$ \\
\hline 9 & 54 & + & 20 & II & 2 & 3 & $\mathrm{~L}^{\mathrm{a}}$ & No (0/19) & + & 15 & NED \\
\hline 10 & 52 & $++^{\mathrm{b}}$ & 25 & $\mathrm{I}$ & 2 & 5 & $\mathrm{~L}$ & No & + & 1 & NED \\
\hline 11 & 63 & $t^{\mathrm{b}}$ & 25 & II & 2 & 5 & $\mathrm{~L}^{\mathrm{a}}$ & No (0/15) & + & 1 & NED \\
\hline 12 & 52 & $t^{\mathrm{b}}$ & 25 & $\mathrm{I}$ & 3 & 7 & $\mathrm{~L}^{\mathrm{c}}$ & No $(1 \mathrm{i}+/ 1)$ & + & 3 & NED \\
\hline 13 & 76 & $t^{\mathrm{b}}$ & 32 & II & 2 & 4 & $\mathrm{M}^{\mathrm{a}}$ & No $(0 / 7)$ & - & 18 & DOC \\
\hline 14 & 51 & + & 30 & II & 3 & 2 & $\mathrm{~L}^{\mathrm{a}}$ & No $(0 / 12)$ & + & 15 & NED \\
\hline 15 & 81 & + & 25 & III & 2 & 3 & None & No & + & 2 & DOD \\
\hline 16 & 32 & - & 20 & $\mathrm{I}$ & 3 & 8 & L & No & - & 3 & NED \\
\hline 17 & ND & ND & ND & $\mathrm{I}$ & 2 & 11 & ND & ND & ND & ND & ND \\
\hline 18 & ND & ND & ND & $\mathrm{I}$ & 2 & 3 & ND & ND & ND & ND & ND \\
\hline
\end{tabular}

Outcome; NED = no evidence of disease; $\mathrm{R}=$ recurrence; $\mathrm{DOD}=$ died of disease; DOC = died of other cause; ND: not determined.

${ }^{\mathrm{a}}$ No sentinel axillary lymph node dissection.

${ }^{b_{\text {Hormone }}}$ replacement therapy; grade according to Kleer and Oberman; MI=mitotic index (on 10 high-power fields); surgical treatment; $\mathrm{M}=$ mastectomy; $\mathrm{L}=$ lumpectomy.

${ }^{\mathrm{c}}$ Sentinel axillary lymph node dissection.

eight cases. The median number of lymph nodes examined was 12 (range: 7-19). No lymph node metastases were seen in either of these cases. An axillary sentinel lymph node procedure was performed in one case (case 12). On serial sectioned hematoxylin-eosin-safran slides, as previously described, ${ }^{18}$ no metastatic involvement was found. According to our protocol, ${ }^{18}$ immunohistochemistry with anticytokeratin (KL1) was then performed on additional tissue sections and a few epithelial cells were subsequently identified. For this patient, no further axillary lymph node dissection was proposed. A toyal of 10 patients received radiotherapy: radiotherapy was administered to one patient as exclusive local and regional treatment. Nine patients received adjuvant radiotherapy. None of the patients received hormonal treatment or chemotherapy. Median follow-up was 6.5 years (range: 1-20).

In all, 12 patients were alive with no evidence of recurrence, 1-15 years after treatment. The patient with cytokeratin-positive cells in the axillary sentinel lymph node was also disease-free after 3 years of follow-up. Two patients presented local recurrence. One of them had two recurrences: one mammary (11 years after primary surgical treatment) and one cutaneous (14 years after primary treatment). Both recurrences were treated by surgery and this woman was still alive 19 years after primary diagnosis. The other patient, who presented local recurrence (13 years) was treated by surgery and radiotherapy. She was alive 16 years after primary surgical treatment. Both women were treated with exclusive surgery with no radiation therapy. One of the 16 patients did not have any surgical treatment and was treated by radiation therapy alone. She developed further progression of disease and died of her disease 2 years after first diagnosis. One patient died from another cause with no evidence of disease.

\section{Pathologic Findings}

Tumor size ranged from 10 to $70 \mathrm{~mm}$, with a mean size of $25 \mathrm{~mm}$. Microscopically, all tumors presented an invasive proliferation. All architectural patterns coexisted, but solid and cribriform patterns were dominant. Tumors showed the distinctive pattern of adenoid cystic carcinoma with true glands and spherules of basement membrane (cylindromatous) material and the two cell types, small dark basal-like cells and larger cuboidal eosinophilic cells. One tumor was both histologic and nuclear grade 1 $(16 \%)$. Nine tumors $(50 \%)$ were nuclear grade 2 , four of them were histologic grade I, three were histologic grade II and two were histologic grade III. Eight tumors (44\%) were nuclear grade 3, two of them were histologic grade I, four were histologic grade II and two were histologic grade III. Mitotic activity ranged from 2 to 11/10 HPF. Necrosis, calcifications and perineural infiltration were absent in all cases. 


\section{Immunohistochemical Findings}

All adenoid cystic carcinoma were negative for ER, PR and HER2.

All cases were positive for CK5/6, CK8/18 and P63 (Table 3). Theses antibodies confirmed the presence of two distinct populations of cells. The first population was composed of cells localized around the glandular lumina, positive for CK8/18 and/or CK $5 / 6$, and the majority of cells were also CK8/18 positive (Figure 1). A minority of cells simultaneously expressed CK5/6 and CK8/18 on double immunostaining (Figure 2a).

The second population consisted of cells localized around the spherules of basement membrane material, and were positive for p63 (Figure 1). No cells were simultaneously stained by double immunostaining using CK5/6 and p63 (Figure 2b).

The percentage of stained cells varied considerably according to the architectural pattern. In tumors with solid areas and rare glandular formations, most cells were positive for myoepithelial markers and a few cells were positive for CK, either CK5/6 or CK8/18. In tumors with a cribriform pattern, $\mathrm{CK}+(\mathrm{CK} 5 / 6$ and $\mathrm{CK} 8 / 18)$ cells surrounded all glandular lumina and cells located in the inner part of the nests were positive for either myoepithelial markers or CK8/18. In areas with a tubular pattern, central ductal elements were CK8/18 and

Table 3 Immunophenotype of adenoid cystic carcinoma of the breast

\begin{tabular}{ccccccccc} 
Case & ER & PR & HER2 & CK5/6 & CK8/18 & $\begin{array}{c}\text { Alpha } \\
\text { smooth } \\
\text { actin }\end{array}$ & P63 & CD117 \\
\hline
\end{tabular}

\begin{tabular}{|c|c|c|c|c|c|c|c|c|}
\hline 1 & 0 & 0 & 0 & $1+$ & $2+$ & $3+$ & $3+$ & $3+$ \\
\hline 2 & 0 & 0 & 0 & $1+$ & $1+$ & $2+$ & $3+$ & $2+$ \\
\hline 3 & 0 & 0 & 0 & $2+$ & $3+$ & $3+$ & $2+$ & $3+$ \\
\hline 4 & 0 & 0 & 0 & $1+$ & $1+$ & $3+$ & $3+$ & $2+$ \\
\hline 5 & 0 & 0 & 0 & $2+$ & $2+$ & $2+$ & $2+$ & $2+$ \\
\hline 6 & 0 & 0 & 0 & $2+$ & $2+$ & $3+$ & $3+$ & $3+$ \\
\hline 7 & 0 & 0 & 0 & $1+$ & $2+$ & $3+$ & $3+$ & $3+$ \\
\hline 8 & 0 & 0 & 0 & $1+$ & $2+$ & $1+$ & $1+$ & $3+$ \\
\hline 9 & 0 & 0 & 0 & $1+$ & $2+$ & $3+$ & $1+$ & $2+$ \\
\hline 10 & 0 & 0 & 0 & $2+$ & $2+$ & $3+$ & $2+$ & nd \\
\hline 11 & 0 & 0 & 0 & $1+$ & $1+$ & $3+$ & $3+$ & $2+$ \\
\hline 12 & 0 & 0 & 0 & $1+$ & $2+$ & $3+$ & $3+$ & $3+$ \\
\hline 13 & 0 & 0 & 0 & $1+$ & $2+$ & nd & nd & nd \\
\hline 14 & 0 & 0 & 0 & $1+$ & $2+$ & $3+$ & $2+$ & $3+$ \\
\hline 15 & 0 & 0 & 0 & $1+$ & $1+$ & $3+$ & $3+$ & $1+$ \\
\hline 16 & 0 & 0 & 0 & $2+$ & $3+$ & $2+$ & $2+$ & $3+$ \\
\hline 17 & 0 & 0 & 0 & $1+$ & $2+$ & $2+$ & $2+$ & $3+$ \\
\hline 18 & 0 & 0 & 0 & $1+$ & $2+$ & $3+$ & $3+$ & $1+$ \\
\hline
\end{tabular}

$\mathrm{O}=$ no cell positive $/ 1+\leq 0 \%$ of cells positive $/ 2+=10$ to $50 \%$ of cells positive $/ 3+\geq 50 \%$ of cells positive.

nd: not determined.
CK5/6 + and cells in contact with the stroma were p63 and SMA positive.

All tumors (16/16, 100\%) expressed KIT protein, with a membranous and/or cytoplasmic immunoreactivity. Nine cases (56\%) showed $3+$ staining, five $(31 \%)$ demonstrated $2+$ staining and two $(12 \%)$ showed only $1+$ staining. The tubular and cribriform patterns (histologic grade I) showed KIT expression in epithelial cells (CK 8/18 and/or 5/6positive), whereas the solid architectural pattern (histologic grade III) showed KIT expression in both cell types. Interestingly, we observed that benign ductal epithelial cells expressed KIT, while normal myoepithelial cells did not express KIT. Two cases of 'classical' invasive ductal breast carcinoma were included as controls for KIT/CD117 immunostaining, neither of them expressed KIT (Figure 3).

\section{Discussion}

In our experience, adenoid cystic carcinoma represents less than $1 \%$ of all mammary tumors and is associated with a very favorable outcome. This tumor has a very specific histologic pattern. It is characterized by glandular lumina and spherules of basement membrane material and by two distinct cell populations, epithelial and myoepithelial cells. A total of 219 adenoid cystic carcinoma of the breast have been reported in the literature.$^{2-6}$ Only seven of these tumors $(3 \%)$ presented axillary lymph node metastasis. In our series, none of the patients had axillary lymph node metastasis. One patient presented cytokeratin-positive cells in the axillary sentinel lymph node. This patient was disease-free after 3 years of follow-up. Axillary lymph node involvement in adenoid cystic carcinoma seems to be a rare phenomenon and does not appear to provide any prognostic information. In agreement with the literature, ${ }^{3}$ we believe that axillary lymph node dissection is not beneficial and therefore should not be indicated. According to the literature, the local recurrence rate after excision is low (ie 14 of the 219 adenoid cystic carcinomas $(6 \%))^{3,19-23}$ In our study, two patients (16\%) presented local recurrence. In both cases, initial treatment consisted of lumpectomy without radiotherapy. These data suggest that radiation after surgery may be important for local control. Moreover, local recurrences may occur many years after the initial diagnosis, as illustrated by the two patients who developed recurrence after 11 and 13 years, respectively. Long-term follow-up of patients with adenoid cystic carcinoma of the breast therefore appears to be

Figure 1 Adenoid cystic carcinoma of the breast with various architectural patterns: cribriform pattern (a-d) and solid pattern (e-h), (hematoxylin-eosin-safran stains, $\mathbf{a}$ and e). Immunohistochemical staining for CK5/6 (b and f), for CK8/18 (c and $\mathbf{g}$ ) and for p63 (d and h). Cells around glandular lumina, are CK8/18 and CK 5/6 positive and the majority of the cells around spherules of basement membrane material, are p63 positive. 

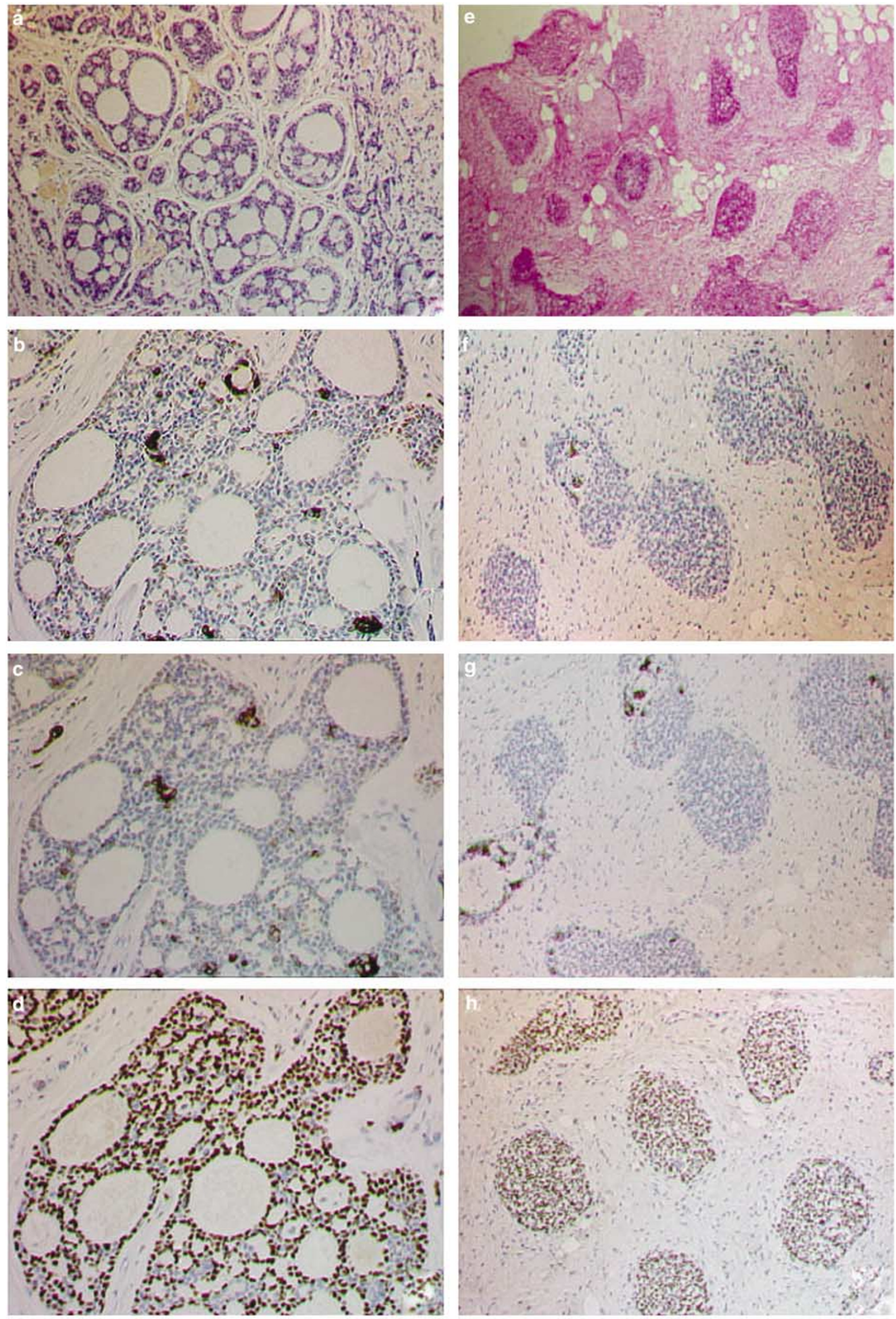

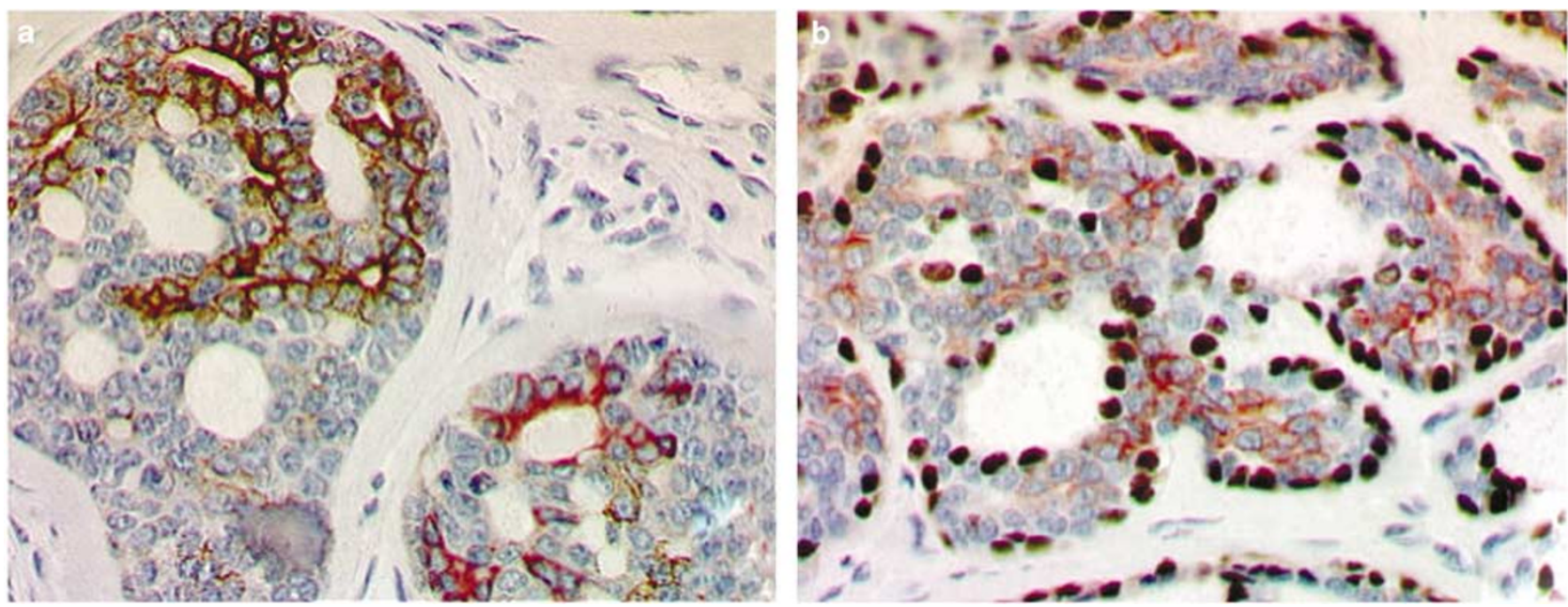

Figure 2 Double immunostaining using CK5/6 (brown cytoplasmic staining) and CK8/18 (red cytoplasmic staining) (a). A few cells coexpressed CK5/6 and CK8/18. Double immunostaining using CK5/6 (red cytoplasmic staining) and p63 (brown nuclear staining) (b). No cells coexpressed CK5/6 and p63.

recommended. Patients with adenoid cystic carcinoma of the breast have an excellent prognosis. Death from adenoid cystic carcinoma was reported in seven cases $(3 \%)$ of 219 adenoid cystic carcinoma. ${ }^{2-4,6}$ One patient in the current series developed progression of disease and died 2 years after diagnosis. Information regarding her treatment revealed that this patient was treated by radiotherapy only without any surgical treatment. In our experience, the most important therapeutic goal is to achieve complete excision with uninvolved margins (mastectomy or lumpectomy according to the tumor size) followed by radiotherapy and long-term follow-up.

In this special histologic type of breast carcinoma, the histologic grading system proposed by Kleer and Oberman, similar to the standard grading system used in breast carcinoma and that used in the present series, is not useful for prognosis. ${ }^{20}$ The two patients who developed recurrence had nuclear grade 1 and 3 tumors, respectively, and the remaining seven patients with nuclear grade 3 tumors were disease free after 10 years of follow-up. The special differentiation of adenoid cystic carcinoma practically ensures the absence of metastatic behavior.

In agreement with several studies, ${ }^{2,9,24,25}$ we observed that adenoid cystic carcinomas are ER, PR and HER-2 negative. In contrast, in a recent study, ${ }^{3}$ Arpino reported ER and PR positivity rates of 46 and $36 \%$, respectively, in adenoid cystic carcinoma of the breast. However, ER and PR status was assessed by biochemical methods, which could have led to false-positive results due to the presence of normal breast tissue in the sample, as previously reported. ${ }^{26}$

p63 was found to be an extremely sensitive and specific marker of myoepithelial cells. In comparison with other myoepithelial markers, such as S100 protein, p63 is the most specific, as it is exclusively restricted to myoepithelial cells. In contrast, S100 protein is poorly specific and although sensitive, is known to also stain stromal myofibroblasts. ${ }^{13}$ Our results clearly showed the presence of myoepithelial cells and highlighted their localization according to their differentiation.

Given the recent introduction of targeted therapy (STI-571, imatinib mesylate (Gleevec), a tyrosine kinase receptor inhibitor) on tumors expressing KIT protein, several studies have evaluated KIT expression in human tissues and neoplasms. In normal tissues, KIT is expressed in hematopoietic stem cells, mast cells, melanocytes, germ cells and interstitial cells of Cajal. ${ }^{27-30}$ In normal mammary epithelium, strong expression of KIT is observed in the cytoplasm and on the cell membrane of ductal epithelial cell, as reported in our study. ${ }^{27,31,32}$ We also observed that myoepithelial cells are KIT negative. In some tumors, CD117 is commonly overexpressed in tumors such as gastrointestinal stromal tumors, ${ }^{33}$ mast cell neoplasms, ${ }^{28}$ renal oncocytomas, chromophobe renal cell carcinomas, seminomas and thymic carcinomas. ${ }^{30}$ Part of this overexpression is associated with the presence of mutations of the KIT gene, such as in gastrointestinal tumors. In invasive breast cancer, KIT immunoreactivity is completely undetectable. ${ }^{31,32,34}$ In our study, two invasive ductal carcinomas were tested with CD117, and none of the neoplastic epithelial cells expressed KIT. In head and neck neoplasms, KIT expression seems to be specific for adenoid cystic carcinoma. Three recent series of adenoid cystic carcinoma of the salivary gland, with 30, 9 and 66 cases, respectively, showed KIT expression in $90,100,94 \%$ of cases. ${ }^{14-16}$ No mutation of the KIT gene has yet been reported in adenoid cystic carcinoma of the salivary glands. We demonstrated that all adenoid cystic carcinomas of breast also expressed KIT (100\%). More than onehalf of them $(56 \%)$ showed intense and diffuse 

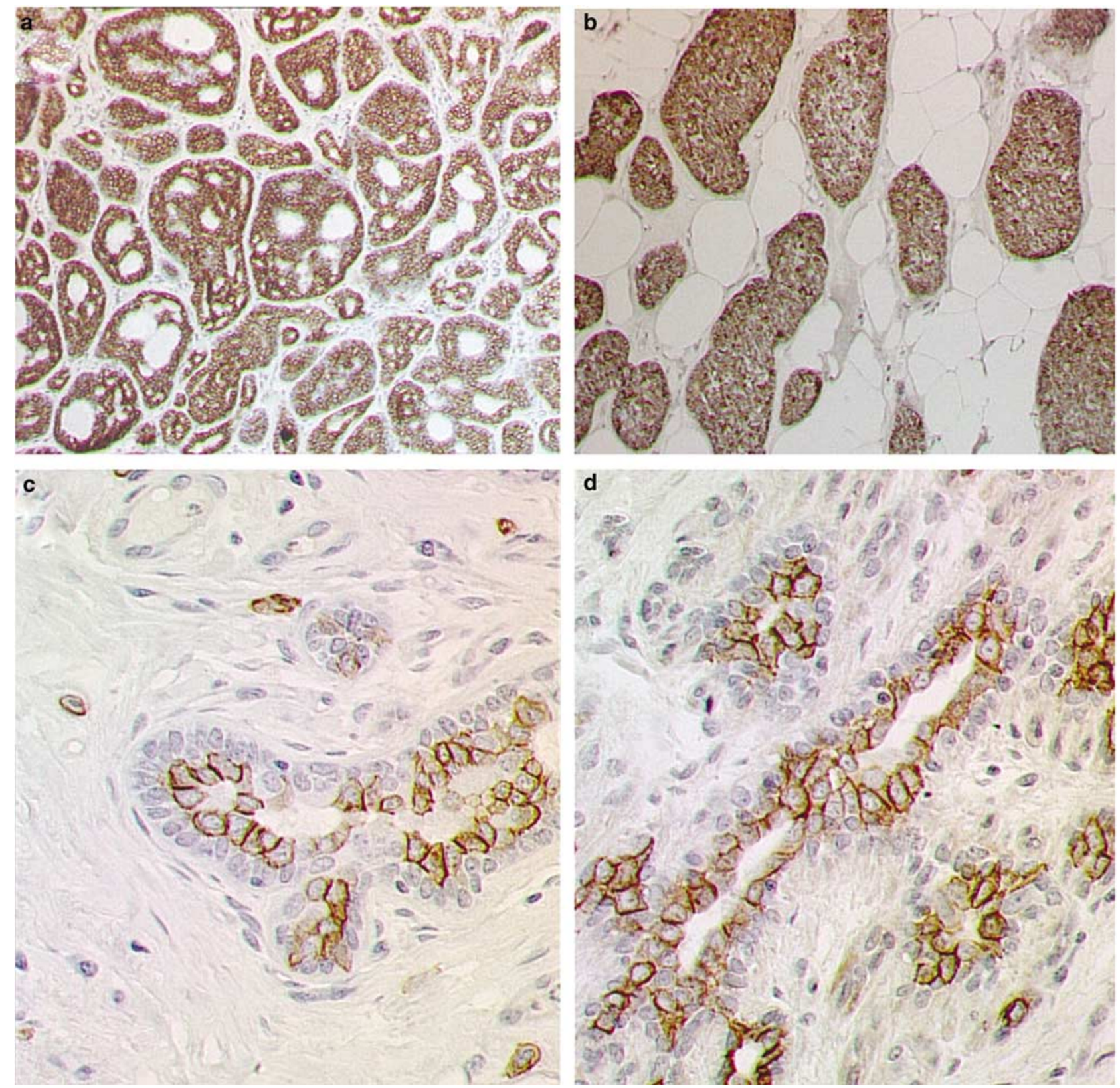

Figure 3 Adenoid cystic carcinoma of the breast with KIT expression: cribriform pattern (a) and solid pattern (b). In the two architectural patterns, more than $90 \%$ of cells expressed KIT, with membranous and/or cytoplasmic immunoreactivity. Normal mammary gland with KIT protein expression (c and d). Benign ductal epithelial cells expressed KIT whereas myoepithelial cells did not express KIT (c and d).

staining. As also observed in adenoid cystic carcinomas of the salivary glands, the pattern of KIT expression in adenoid cystic carcinomas of breast differs according to the histologic subtype. Tubular and cribriform variants showed KIT expression limited to epithelial cells. In contrast, solid variants showed KIT expression in the great majority of cells, most of which are considered to be myoepithelial cells. Therefore, KIT expression can be used to differentiate adenoid cystic carcinoma from cribriform carcinoma of the breast. ${ }^{35}$

All adenoid cystic carcinomas of the breast expressed CK5/6, CK8/18 and p63, but the distribu- tion of this expression varied considerably according to the pattern of the tumor. In cribriform and tubular areas, CK5/6- and CK8/18-positive cells were found around glandular lumina and alpha smooth actin/p63-positive cells lined spherules of basement membrane material. In solid areas, p63positive cells were predominant. By classifying breast cell populations according to the system proposed by Bocker, ${ }^{36}$ we identified four distinct types of cells in adenoid cystic carcinoma of the breast; rare $\mathrm{CK} 5 / 6+$ cells $(\mathrm{CK} 8 / 18-/ \mathrm{p} 63-)$ or progenitor cells, CK5/6+/CK8/18 + cells (/p63-) or glandular precursor cells, CK8/18+ cells 
(CK5/6-/P63-), or glandular end cells and p63+ cells (CK5/6-/CK8/18-) or myoepithelial cells. Although the origin of adenoid cystic carcinoma of the breast is still debated, it seems to be widely accepted that this tumor is derived from undifferentiated cells, which have the capacity to differentiate towards ductal and myoepithelial cells. ${ }^{9,10,25,37}$ Our study confirmed this theory, as we demonstrated the presence of CK5/6 + cells that could represent precursor cells. However, even by using a double immunostaining procedure, we were unable to identify a CK5/6+/P63 + population of cells which could correspond to myoepithelial precursor cells. The absence of these cell types could be explained by two hypotheses. Two different population of cells, epithelial and myoepithelial, proliferate independently and lead to the formation of adenoid cystic carcinoma, while the transformation of CK5/6 + precursor cells into P63 + myoepithelial cells occurs very rapidly and could not be identified by immunohistochemistry.

Perou et $a l^{38}$ using cDNA gene expression analysis identified two groups of breast carcinomas: luminal and basal carcinomas. The basal group of tumors was associated with a poor outcome compared to luminal tumors. ${ }^{39}$ Nielsen et al and Van de Rijn et al reported that basal carcinomas were characterized by a specific immunophenotype ER/PR/HER2 negative and CK5/6/or 14 or 17 positive, HER ${ }^{39}$ and KIT positive. ${ }^{40}$ In a recent series of 1944 invasive breast carcinomas, El Rehin et al ${ }^{11}$ subdivided the cases into four different cellular phenotypes: luminal $(71 \%)$ (tumors expressing one or more luminal markers)/combined luminal and basal $(27 \%)$ (tumors positive for one or more luminal markers together with one or more basal markers)/ basal $(0.8 \%)$ (tumors expressing only one or more basal markers)/null (0.4\%) (tumors negative for both luminal and basal markers). These observations led us to consider adenoid cystic carcinoma to be a special form of 'basal-like' breast tumor, paradoxically associated with a favorable outcome. In this context, the biological mechanisms underlying the favorable behavior of adenoid cystic carcinoma of the breast have yet to be elucidated.

In conclusion, adenoid cystic carcinoma of the breast is a subtype of breast carcinoma with an excellent prognosis characterized by a distinct morphology and immunohistochemical profiles. Appropriate clinical management of adenoid cystic carcinoma of the breast requires complete local and regional treatment including surgery and radiotherapy. However, in our experience, axillary lymph node dissection does not appear to be necessary. Immunohistochemical analysis using the above markers could help when dealing with difficult histologic cases, as, to our knowledge, adenoid cystic carcinoma of the breast is the only breast tumor that is ER, PR, HER-2 negative, KIT positive and that expresses both epithelial (basal and luminal CK) and myoepithelial markers.

\section{Acknowledgements}

We thank Danièle Chazal for her technical assistance and Annie Le Cunff for her help in finalizing the manuscript.

\section{References}

1 Tavassoli F. Pathology of the breast, 2nd edn. Appleton and Lange: New York, 1999.

2 Ro JY, Silva EG, Gallager HS. Adenoid cystic carcinoma of the breast. Hum Pathol 1987;18:1276-1281.

3 Arpino G, Clark GM, Mohsin S, et al. Adenoid cystic carcinoma of the breast: molecular markers, treatment, and clinical outcome. Cancer 2002;94:2119-2127.

4 Wells CA, Nicoll S, Ferguson DJ. Adenoid cystic carcinoma of the breast: a case with axillary lymph node metastasis. Histopathology 1986;10:415-424.

5 Pastolero G, Hanna W, Zbieranowski I, et al. Proliferative activity and p53 expression in adenoid cystic carcinoma of the breast. Mod Pathol 1996;9:215-219.

6 Verani RR, Van der Bel-Kahn J. Mammary adenoid cystic carcinoma with unusual features. Am J Clin Pathol 1973;59:653-658.

7 Kasami M, Olson SJ, Simpson JF, et al. Maintenance of polarity and a dual cell population in adenoid cystic carcinoma of the breast: an immunohistochemical study. Histopathology 1998;32:232-238.

8 Trojani M, de Mascarel I, Coindre JM. Adenoid cystic carcinoma of the breast. Value of immunohistochemical study in diagnosis. Tumori 1991;77:130-135.

9 Due W, Herbst WD, Loy V, et al. Characterisation of adenoid cystic carcinoma of the breast by immunohistology. J Clin Pathol 1989;42:470-476.

10 Lamovec J, Us-Krasovec M, Zidar A, et al. Adenoid cystic carcinoma of the breast: a histologic, cytologic, and immunohistochemical study. Semin Diagn Pathol 1989;6:153-164.

11 Abd El-Rehim DM, Pinder SE, Paish CE, et al. Expression of luminal and basal cytokeratins in human breast carcinoma. J Pathol 2004;203:661-671.

12 Bocker W, Moll R, Poremba C, et al. Common adult stem cells in the human breast give rise to glandular and myoepithelial cell lineages: a new cell biological concept. Lab Invest 2002;82:737-746.

13 Barbareschi M, Pecciarini L, Cangi MG, et al. p63, a p53 homologue, is a selective nuclear marker of myoepithelial cells of the human breast. Am J Surg Pathol 2001;25:1054-1060.

14 Holst VA, Marshall CE, Moskaluk CA. KIT protein expression and analysis of c-kit gene mutation in adenoid cystic carcinoma. Mod Pathol 1999;12:956-960.

15 Penner CR, Folpe AL, Budnick SD. C-kit expression distinguishes salivary gland adenoid cystic carcinoma from polymorphous low-grade adenocarcinoma. Mod Pathol 2002;15:687-691.

16 Mino M, Pilch BZ, Faquin WC. Expression of KIT (CD117) in neoplasms of the head and neck: an ancillary marker for adenoid cystic carcinoma. Mod Pathol 2003;16:1224-1231.

17 Vincent-Salomon A, Mac Grogan G, Couturier J, et al. Calibration of immunohistochemistry for assessment of HER2 in breast cancer: results of the French multicentric GEFPICS study. Histopathology 2003;42: $337-347$. 
18 Freneaux P, Nos C, Vincent-Salomon A, et al. Histological detection of minimal metastatic involvement in axillary sentinel nodes: a rational basis for a sensitive methodology usable in daily practice. Mod Pathol 2002;15:641-646.

19 Cavanzo T. Adenoid cystic carcinoma of the breast. An analysis of 21 cases. Cancer 1969;24:740-745.

20 Kleer CG, Oberman HA. Adenoid cystic carcinoma of the breast: value of histologic grading and proliferative activity. Am J Surg Pathol 1998;22:569-575.

21 Peters GN, Wolff M. Adenoid cystic carcinoma of the breast. Report of 11 new cases: review of the literature and discussion of biological behavior. Cancer 1983; 52:680-686.

22 Qizilbash AH, Patterson MC, Oliveira KF. Adenoid cystic carcinoma of the breast. Light and electron microscopy and a brief review of the literature. Arch Pathol Lab Med 1977;101:302-306.

23 Wilson WB, Spell JP. Adenoid cystic carcinoma of breast: a case with recurrence and regional metastasis. Ann Surg 1967;166:861-864.

24 Trendell-Smith NJ, Peston D, Shousha S. Adenoid cystic carcinoma of the breast: a tumour commonly devoid of oestrogen receptors and related proteins. Histopathology 1999;35:241-248.

25 Shin SJ, Rosen PP. Solid variant of mammary adenoid cystic carcinoma with basaloid features: a study of nine cases. Am J Surg Pathol 2002;26:413-420.

26 Zafrani B, Aubriot M, Mouret E, et al. High sensitivity and specificity of immunohistochemistry for the detection of hormone receptors in breast carcinomas: comparison with biochemical determination in a prospective study of 793 cases. Histopathology 2000; 37:536-545.

27 Tsuura Y, Hiraki H, Watanabe K, et al. Preferential localization of c-kit product in tissue mast cells, basal cells of skin, epithelial cells of breast, small cell lung carcinoma and seminoma/dysgerminoma in human: immunohistochemical study on formalinfixed, paraffin-embedded tissues. Virchows Arch 1994; 424:135-141.

28 Arber DA, Tamayo R, Weiss LM. Paraffin section detection of the c-kit gene product (CD117) in human tissues: value in the diagnosis of mast cell disorders. Hum Pathol 1998;29:498-504.
29 Heinrich M, Rubin B, Longley B, et al. Biology and genetic aspects of gastrointestinal stromal tumors: KIT activation and cytogenetic alterations. Hum Pathol 2002;33:484-495.

30 Pan CC, Chen PC, Chiang H. KIT (CD117) is frequently overexpressed in thymic carcinomas but is absent in thymomas. J Pathol 2004;202:375-381.

31 Chui X, Egami H, Yamashita J, et al. Immunohistochemical expression of the c-kit proto-oncogene product in human malignant and non-malignant breast tissues. Br J Cancer 1996;73:1233-1236.

32 Ulivi P, Zoli W, Medri L, et al. c-kit and SCF expression in normal and tumor breast tissue. Breast Cancer Res Treat 2004;83:33-42.

33 Fletcher JA, Fletcher CDM, Rubin BP, et al. KIT gene mutations in gastrointestinal stromal tumors: more complex than previously recognized? Am J Pathol 2002;161:737-739.

34 Simon R, Panussis S, Maurer R, et al. KIT (CD117)positive breast cancers are infrequent and lack KIT gene mutations. Clin Cancer Res 2004;10: 178-183.

35 Swain RS, Zaloudek C, Chase DR, et al. Adenoid cystic carcinoma of the breast is distinguished from collagenous spherulosis and cribriform ductal carcinoma in situ by CD117 and calponin immunohistochemistry. Mod Pathol 2005;18:51A.

36 Bocker W, Moll R, Poremba C, et al. Common adult stem cells in the human breast give rise to glandular and myoepithelial cell lineages: a new cell biological concept. Lab Invest 2002;82:737-746.

37 Azumi N, Battifora $H$. The cellular composition of adenoid cystic carcinoma. An immunohistochemical study. Cancer 1987;60:1589-1598.

38 Perou CM, Sorlie T, Eisen MB, et al. Molecular portraits of human breast tumours. Nature 2000;406: 747-752.

39 van de Rijn M, Perou CM, Tibshirani R, et al. Expression of cytokeratins 17 and 5 identifies a group of breast carcinomas with poor clinical outcome. Am J Pathol 2002;161:1991-1996.

40 Nielsen TO, Hsu FD, Jensen K, et al. Immunohistochemical and clinical characterization of the basal-like subtype of invasive breast carcinoma. Clin Cancer Res 2004;10:5367-5374. 